\title{
Determinants of intentions to quit smoking among adult smokers in Bangladesh: findings from the International Tobacco Control (ITC) Bangladesh wave 2 survey
}

Pete Driezen ${ }^{1}$, Abu S. Abdullah ${ }^{2,3,4^{*}}$ (D) Anne C. K. Quah ${ }^{1}$, Nigar Nargis ${ }^{5,6}$ and Geoffrey T. Fong ${ }^{1,7}$

\begin{abstract}
Background: With about 22 million adult smokers, Bangladesh needs strong measures that would promote smoking cessation. Using data from Wave 2 of the International Tobacco Control (ITC) Survey, this study examined the factors associated with intention to quit smoking among Bangladeshi smokers.

Methods: Data from Wave 2 of the International Tobacco Control (ITC) Survey in Bangladesh, a face to face survey of adult smokers, were analysed. In the ITC survey, households were sampled using a stratified multistage design and interviewed using a structured questionnaire.

Results: Of the respondents ( $N=2982)$, most were male (96\%), married (80\%), and Muslim (83\%); $33 \%$ were illiterate and $54 \%$ were aged below 40 . Almost two-thirds were from areas outside Dhaka, $78 \%$ smoked cigarettes exclusively; and $36 \%$ had an intention to quit smoking in the future. This study identified several predictors, comparable to other international studies, of intention to quit smoking: area of residence, number of cigarettes smoked daily, previous quit attempt, visiting a doctor in the past, having child aged 5 or below at home, perceived benefit from quitting, being worried about own health, knowledge of SHS, not enjoying smoking and workplace smoking policy.

Conclusions: These findings suggest that the prevalence of intention to quit smoking is lower among Bangladeshi smokers than those among smokers in developed countries. However, the factors relating to quit intentions among Bangladeshi smokers are comparable to those found in Western countries. Population based tobacco control programs and policies should consider these predictors in the design of interventions to increase quitting among smokers in Bangladesh.
\end{abstract}

Keywords: Smoking, Intention to quit, Bangladesh, Determinants

Abbreviations: AIC, Akaike information criterion; BDT, Bangladeshi Taka; ITC, International Tobacco Control Policy Evaluation Project; SHS, Second-hand smoke; WHO, World Health Organization

\footnotetext{
* Correspondence: asm.abdullah@graduate.hku.hk

${ }^{2}$ Global Health Program, Duke Kunshan University, Kunshan, Jiangsu Province 215347, China

${ }^{3}$ Duke Global Health Institute, Duke University, Durham, NC 27710, USA

Full list of author information is available at the end of the article
} 


\section{Background}

Tobacco smoking, including second hand smoke, is one of the leading risk factors for global disease burden accounting for $6.3 \%$ of global disability adjusted life years (DALYS) [1]. Annual deaths attributed to tobacco smoking will rise from approximately 5 million in 2010 to more than 10 million in the next few decades if the current patterns of smoking and quitting do not change [2, 3]. The 2013 World Health Assembly called on governments to reduce the prevalence of smoking by a third by 2025, which would prevent more than 200 million deaths from tobacco during the remainder of the century [2]. Promotion of smoking cessation has been proposed as one of the primary areas of focus for tobacco control in developing countries [4].

Quitting smoking is beneficial and increases life expectancy among smokers [1], regardless of the timing of cessation. However, giving up smoking is not a single act. Rather, smoking cessation is a process that progresses through several stages described by Prochaska and DiClemente in their transtheoretical stages of change model [5]. As people's readiness to change shifts when they move through the various stages, interventions must be tailored to target the specific stage $[6,7]$.

Previous research in different countries has identified several factors associated with intentions to quit, including socioeconomic factors [8-11], positive attitude towards quitting [12-14], perceiving more behavioral control over quitting $[13,14]$ perceiving quitting as a priority [14], health concerns $[12,15]$, having received medical advice to quit smoking [15], perceived social pressure [16, 17], expected social support for quitting $[15,17]$, higher self-efficacy [16], having confidence to quit [12], being older [12, 18], consuming fewer cigarettes $[13,19,20]$, lower nicotine dependence level [21], and past quitting attempt $[12,13,16,20]$.

A study of Korean adults found that sociodemographic factors, smoking-related beliefs, and smoking restrictions at home were associated with intention to quit smoking [22]. In another study of adult Chinese smokers, many of these same factors (i.e., past quit attempts, duration of past quit attempts, nicotine dependence level, outcome expectancy and opinion of smoking) were associated with intentions to quit smoking, although demographic factors were not [23].

Bangladesh is one of the top ten countries in the world with high current smoking prevalence of $44.7 \%$ among men [24]. This country is distinguished as the first signatory of the World Health Organization (WHO) Framework Convention on Tobacco Control (WHO FCTC) which was ratified on 10 May 2004. The ratification was made concrete with the passage of the Tobacco Control Act (TCA) on 15 March 2005. To our knowledge, no population based studies of intentions to quit smoking have been conducted in Bangladesh - a country with 22 million adult smokers [24]. This lack of evidence has hindered the development of effective policies to promote smoking cessation interventions [25]. In this study, we examined the associations between intentions to quit smoking and a range of factors, including sociodemographic characteristics, tobacco use behaviors, tobacco use attitudes, worries about health, and knowledge of the harms of tobacco smoking among a nationally representative sample of Bangladeshi adults.

\section{Methods}

\section{Sample}

The data for this study come from Wave 2 (March 2010 to June 2010) of the International Tobacco Control (ITC) Policy Evaluation Bangladesh Survey, a nationally representative prospective cohort survey of smokers and non-smokers aged 15 and older [26, 27]. Respondents were sampled from all six administrative divisions of Bangladesh using a stratified multi-stage probability design. Respondents were also sampled from Dhaka's urban slums to represent the urban poor, from two tribal districts to study tobacco use in the Garo and Chakma indigenous populations, and from a land port bordering India thought to be important for cross-border tobacco trade.

In Wave 2, 3111 Wave 1 smokers were re-contacted and 622 additional smokers were recruited to replace Wave 1 respondents lost to attrition. New respondents were recruited using the same sampling design as Wave 1. Data were collected using face-to-face interviews and sampling weights were computed so that results represent the population of adult smokers. The analysis reported here is based on 2982 current smokers in Wave 2, 2337 of whom smoked cigarettes, 368 of whom smoked bidis and 277 of whom smoked both cigarettes and bidis. Complete details of the ITC Bangladesh survey are available elsewhere [28]. Ethical approval was obtained from the Office of Research Ethics at the University of Waterloo (Waterloo, Canada), and the Ethical Review Committee, Bangladesh Medical Research Council.

\section{Measures \\ Primary outcome measure}

The primary outcome measure for this study was intentions to quit smoking. Current smokers were asked whether they were planning to quit smoking "Within the next month," "Within the next 6 months," or "Sometime in the future, beyond 6 months." Smokers could also report that they were "Not planning to quit." In this study, quit intentions were dichotomized into "any intention to quit" versus "no intention to quit". 


\section{Predictor variables}

The ITC Bangladesh survey measures a broad range of domains related to tobacco use, attitudes toward and perceptions of tobacco control policies. Relevant domains for this study include socio-demographic characteristics, tobacco use behaviours, tobacco use attitudes, worries about health, and knowledge of the harms of tobacco smoking.

\section{Socio-demographic measures}

Respondents were characterized according to their sex, age, religion (Muslim vs. non-Muslim), residence (Dhaka city, urban slums within Dhaka, areas outside Dhaka, and tribal/border areas), and marital status (married vs. not married). The ITC Bangladesh survey also assessed respondents' highest level of formal education (illiterate, 1-8 years, 9 years or more), monthly household income $(<5000$ BDT, 5000-10,000 BDT, $>10,000$ BDT and not reported) (IUS $\$=79 \mathrm{BDT}$ ), and the number of smokers living in each respondent's home.

\section{Tobacco use and prior attempts to quit}

Respondents were classified into three different tobacco use categories on the basis of whether they exclusively smoked cigarettes or bidis or whether they smoked cigarettes and bidis (dual use). Usual tobacco consumption was based on the self-reported number of cigarettes or bidis smoked each day for cigarette smokers and bidi smokers, respectively. For dual users, total consumption was based on the number of cigarettes and bidis smoked each day. Respondents were also asked how many of their friends or acquaintances currently smoke (0 to 5$)$.

With respect to previous attempts to quit smoking, respondents were asked whether they had tried to quit smoking in the past year. Based on their responses, respondents were classified into those smokers who made at least one attempt vs. smokers who did not try to quit in the past year. Smokers were also asked to report the longest time they had ever been smoke-free. Responses were classified into " $<1$ month," "1-6 months," " $>6$ months" or "don't know". Finally, respondents were asked whether they had been to a doctor in the last year, and, if so, whether they had been advised to quit smoking.

\section{Motivational factors}

Smokers' motivation to quit smoking was assessed by measuring (a) their opinions of cigarette and bidi smoking, (b) their expectations of future health effects if they quit smoking (outcome expectancy), (c) their level of worry about the health consequences of smoking and (d) whether they had favourable attitudes toward smoking. Opinions of cigarette smoking were classified as good or neutral vs. bad and very bad. Outcome expectancy was assessed using the question "How much do you think you would benefit from health and other gains if you were to quit smoking cigarettes permanently in the next 6 months?" Responses ranged from $1=$ "not at all" to $5=$ "extremely". Concern about health was assessed by the question "How worried are you, if at all, that smoking cigarettes will damage your health in the future?" Possible responses were "not at all worried," "a little worried," "moderately worried" and "very worried." Finally, respondents were asked whether they enjoy smoking too much to give it up. Responses were classified on a 5 point Likert scale from $1=$ "strongly agree" to $5=$ "strongly disagree." Note that smokers could report "don't know" to any of these items. These responses were retained in the analysis reported here and treated as an "ambivalent" category.

\section{Policy relevant measures}

To assess whether policy related measures might influence smokers' intentions to quit, smokers were asked (a) how often in the last month they noticed warning labels (never, once in a while, often, very often) and (b) whether smoking is banned in indoor areas in their workplace. Responses were classified into: does not work outside the home, works outside only, no restrictions or only partial restrictions and smoking is not allowed indoors. Respondents who were employed but did not report their workplace smoking policy were retained in the analysis using the category "Employed, policy not reported".

\section{Knowledge of health effects}

Finally, two composite measures assessed smokers' knowledge of the harmful effects of (a) smoking and (b) exposure to second hand smoke. Knowledge of the harmful effects of smoking was assessed using 14 separate measures of health effects including knowledge of whether cigarette smoking causes stroke, impotence, mouth cancer, lung cancer, coronary heart disease, tuberculosis, and bronchitis and whether bidi smoking causes each of these outcomes. Affirmative responses to each item were coded with a value of 1 while all other responses were coded as 0 . An overall knowledge score was created by summing each of these items. Similarly, knowledge of the harms of second-hand smoke was assessed by affirmative responses to whether secondhand smoke causes lung cancer in non-smokers, heart disease in non-smokers, asthma in children and tuberculosis. Again, an overall knowledge score was created by summing these four items.

\section{Statistical analysis}

Unless otherwise noted, all statistical estimates and tests presented here were weighted using the Wave 2 crosssectional sampling weight to ensure that results represent 
the population of adult smokers in Bangladesh. Statistical analysis, conducted using SAS version 9.4, accounted for the complex survey design. Descriptive statistics were used to estimate the percentage of smokers intending to quit smoking by important socio-demographic and tobacco use variables. Bivariate associations between quit intentions and socio-demographic, behavioural, motivational, and policy measures were assessed using the Rao-Scott $\chi^{2}$ test. Differences in quit intentions by health knowledge were assessed using univariate linear regression models.

Binary logistic regression was used to estimate associations between independent predictors and intentions to quit smoking (any intention vs. no intention). All covariates described above were entered into an initial model and a final model was built using a backward selection procedure. Variables used in the construction of sampling weights (residence, sex and tobacco use), along with age, were forced into the model. In each step of the model building procedure, a sub-model was estimated by removing one covariate at a time. The Akaike information criterion (AIC) was computed for each sub-model. The submodel having the smallest AIC statistic after removing a covariate was then selected as the best fitting sub-model. This procedure was repeated until removal of variables no longer improved model fit (i.e., no sub-model produced a smaller value for the AIC statistic). The final selected model was then re-fit using only the selected covariates in order to use as many observations as possible to predict quit intentions.

\section{Results}

\section{Profile of subjects}

Of the respondents $(N=2982)$, most were male (96\%), married (80 \%), and Muslim (83 \%); $33 \%$ were illiterate and $54 \%$ were aged below 40 . Almost twothirds were from areas outside Dhaka, while $22 \%$ were from Dhaka's urban slums (Table 1). The majority of the sample smoked cigarettes exclusively (78 \%) and did not try to quit in the past year (82\%).

\section{Patterns of intention to quit}

Overall, $36 \%$ of Bangladeshi smokers intended to quit smoking tobacco in 2010 (95 \% CI: 31.9-41.2 \%). With the exception of residence, quit intentions did not significantly differ by the socio-demographic characteristics of Bangladeshi smokers (Table 2). However, a smaller percentage of smokers from the tribal or border areas planned to quit smoking compared to smokers living non-tribal areas outside Dhaka (25 vs $38 \%$, respectively). Only $28 \%$ of bidi smokers planned to quit, compared to $37 \%$ of cigarette smokers and $43 \%$ of dual users $(p=0.054)$.

\section{Predictors of intention to quit}

Several behavioural, motivational, policy and knowledge measures were significantly associated with intentions to quit smoking, as presented in Table 3. Table 4 presents the results of the multivariable logistic regression model developed to examine correlates of quit intentions after adjusting for other covariates. Not all covariates presented in Table 3 were chosen by the selection procedure for inclusion in the final logistic regression model. However, all relationships between covariates and quit intentions in the multivariable model were consistent with the bivariate relationships presented in Table 3. With respect to behavioural variables, smokers smoking fewer cigarettes per day had significantly higher odds of planning to quit compared to smokers smoking 21 or more cigarettes per day. Similarly, smokers who ever tried to quit had 2.8 times higher odds of planning to quit compared to smokers who had never tried to quit. Receiving advice to quit from a doctor also influence the odds of planning to quit smoking ( $\mathrm{OR}=1.86$, compared to smokers who did not visit a doctor in the past 6 months).

Motivational factors influence the odds of planning to quit. Smokers who believed there was great benefit in quitting had 2.1 times higher odds of planning to quit compared to smokers who saw little benefit in quitting. Enjoyment of smoking also predicted the odds of planning to quit: smokers who do not enjoy smoking had 1.4 times higher odds of planning to quit compared to smokers who enjoy smoking. Smokers' concern about the health consequences significantly influenced their odds of planning to quit: smokers who were very worried about their health had 8.7 times higher odds of planning to quit compared to smokers who were not at all worried. Even small amounts of concern were associated with higher odds of planning to quit such that smokers who were moderately worried had 4.2 times higher odds of planning to quit and smokers who were only a little worried about health had 3.9 times the odds of planning to quit.

Tobacco control policies may influence smokers' intentions to quit. Specifically, smokers employed in indoor areas where smoking is banned had 2.0 times higher odds of planing to quit compared to smokers who worked outdoors. Even partial bans were associated with intentions to quit $(\mathrm{OR}=1.73)$. Furthermore, knowledge of the harmful effects of second-hand smoke was associated with increased odds of planning to quit. Similarly, smokers living in homes with children aged 5 or younger had significantly higher odds of planning to quit compared to smokers having no children in the home $(\mathrm{OR}=1.62)$. However, awareness of the harmful effects of smoking on one's own health was not associated with intentions to quit $(p=0.09)$. 
Table 1 Characteristics of the ITC Bangladesh Wave 2 sample of tobacco smokers (unweighted, $n=2982$ )

\begin{tabular}{|c|c|c|c|}
\hline & Frequency (\%) & Dual user & $277(9.3)$ \\
\hline Wave of recruitment & & Amount smoked/day & \\
\hline 1 & $2361(79.2)$ & $<=10$ sticks/day & $1801(61.9)$ \\
\hline 2 & $621(20.8)$ & 11-20 sticks/day & $870(29.9)$ \\
\hline Area sample & & $21+$ sticks/day & $237(8.1)$ \\
\hline Dhaka (non-slum) & $333(11.2)$ & Made a quit attempt in past year & \\
\hline Dhaka slums & $649(21.8)$ & No attempts in past year & $2383(81.6)$ \\
\hline Areas outside Dhaka & $1862(62.4)$ & At least one attempt in past year & $537(18.4)$ \\
\hline
\end{tabular}

Sex

Male

Female

Age

15-24

35-39

40-54

$55+$

Marital status

Married

Otherwise

Religion

Otherwise

497 (16.7)

Muslim

$2483(83.3)$

Highest level of education

Illiterate

1002 (33.6)

1-8 years

$1428(47.9)$

$9+$ years

$550(18.5)$

Monthly household income

$<5000$ BDT

5000 to $<10,000$ BDT

10,000 BDT or more

Not reported

Children in household

No children in home

Only children 5 or younger

Only children aged 6 to 14

Children 14 or younger

No. household smokers

1
2
3 or more
obacco use status
Exclusive cigarette smoker
Exclusive bidi smoker

$1115(37.4)$

$1306(43.8)$

$561(18.8)$

$2337(78.4)$

368 (12.3)
Table 1 Characteristics of the ITC Bangladesh Wave 2 sample of tobacco smokers (unweighted, $n=2982$ ) (Continued)

Additional factors not included in the final multivariable model may influence smokers' intentions to quit. The percentage of smokers who planned to quit was lower among smokers having a greater number of friends who smoke: $31 \%$ of smokers with five smoking friends planned to quit compared to $52 \%$ of smokers having only two smoking friends (Table 3). Likewise, only $24 \%$ of smokers who never tried to quit planned to quit compared to $53 \%$ of smokers who had previously quit for one to six months. Approximately one-third of smokers having negative opinions of cigarette, bidi, or hookah smoking planned to quit while smokers having positive opinions of tobacco smoking were less likely to plan to quit.

\section{Discussions}

This is the first nationally representative survey to study predictors of intentions to quit smoking among Bangladeshi adults. The findings demonstrate that interest in quitting among adult Bangladeshi smokers is low (36\%) compared to the rates in developed regions or countries. For example, 52 \% of Hong Kong Chinese plan to quit [29], and rates in many developed countries of the West are even higher, ranging from 65 to $81 \%$ [30]. Among Korean adults, $75 \%$ of adult smokers plan to quit [22]. However, only $15 \%$ of Chinese adult smokers plan to quit (range 15 to $31 \%$ ) [23]. Even though the percentage of smokers planning to quit in our study was higher than the reported rates among Chinese smokers [23], the percentage is low. This low quitting intention among Bangladeshi smokers is due to several factors, including lack of public health campaigns that focus on the benefits and harms of quitting smoking, lack of smoking cessation programs (e.g., quitline or clinic) that are available in Bangladesh, and the lack of available smoking cessation medications in Bangladesh. The low rate of quitting intention among the Bangladeshi adults underscore the need for comprehensive policy initiatives that would encourage smokers to think about quitting. At the same time, the national tobacco control program, 
Table 2 Percentage of adult smokers in Bangladesh having any plans to quit smoking (weighted, $n=2884$ )

\begin{tabular}{|c|c|c|c|c|c|}
\hline & \multirow[t]{2}{*}{ (Unwtd. Freq.) } & \multirow[t]{2}{*}{$\%(95 \% \mathrm{Cl})$} & \multicolumn{3}{|c|}{ Rao-Scott ChiSq Test } \\
\hline & & & $\overline{x^{2}}$ & DF & $p$ \\
\hline \multicolumn{6}{|l|}{ Overall } \\
\hline Prevalence & $(901 / 2884)$ & $36.4(31.9,41.2)$ & & & \\
\hline \multicolumn{6}{|l|}{ Area sample } \\
\hline Dhaka (non-slum) & $(98 / 333)$ & $29.3(14.8,49.7)$ & 8.27 & 3 & 0.041 \\
\hline Dhaka slums & $(101 / 646)$ & $20.1(8.1,41.8)$ & & & \\
\hline Areas outside Dhaka & $(670 / 1769)$ & $38.1(33.4,43.0)$ & & & \\
\hline Tribal/border areas & $(32 / 136)$ & $24.7(20.8,29.1)$ & & & \\
\hline \multicolumn{6}{|l|}{ Sex } \\
\hline Male & $(859 / 2755)$ & $36.3(32.0,40.9)$ & 0.14 & 1 & 0.713 \\
\hline Female & $(42 / 129)$ & $39.5(22.6,59.3)$ & & & \\
\hline \multicolumn{6}{|l|}{ Age } \\
\hline $15-24$ & $(157 / 503)$ & $36.0(28.2,44.7)$ & 4.24 & 3 & 0.237 \\
\hline $35-39$ & $(310 / 1083)$ & $32.8(26.7,39.5)$ & & & \\
\hline $40-54$ & $(243 / 764)$ & $37.4(30.8,44.6)$ & & & \\
\hline $55+$ & $(191 / 534)$ & $41.7(33.9,49.9)$ & & & \\
\hline \multicolumn{6}{|l|}{ Marital status } \\
\hline Married & $(721 / 2295)$ & $36.1(31.5,40.9)$ & 0.23 & 1 & 0.629 \\
\hline Otherwise & $(177 / 584)$ & $37.8(30.3,46.0)$ & & & \\
\hline \multicolumn{6}{|l|}{ Religion } \\
\hline Muslim & $(753 / 2415)$ & $37.3(32.2,42.6)$ & 0.94 & 1 & 0.333 \\
\hline Otherwise & $(148 / 467)$ & $32.4(24.2,41.8)$ & & & \\
\hline \multicolumn{6}{|l|}{ Highest level of education } \\
\hline Illiterate & $(267 / 945)$ & $34.7(28.4,41.6)$ & 2.38 & 2 & 0.305 \\
\hline $1-8$ years & $(444 / 1392)$ & $35.9(30.6,41.5)$ & & & \\
\hline $9+$ years & $(190 / 545)$ & $41.6(33.6,50.0)$ & & & \\
\hline \multicolumn{6}{|l|}{ Monthly household income } \\
\hline$<5000$ taka & $(114 / 416)$ & $31.3(23.9,39.8)$ & 5.60 & 3 & 0.133 \\
\hline 5000 to $<10,000$ taka & $(414 / 1343)$ & $34.8(29.1,40.9)$ & & & \\
\hline 10,000 taka or more & $(335 / 987)$ & $41.6(35.8,47.6)$ & & & \\
\hline Not reported & $(38 / 138)$ & $37.5(23.7,53.6)$ & & & \\
\hline \multicolumn{6}{|l|}{ Children in household } \\
\hline No children in home & $(230 / 763)$ & $36.9(31.8,42.2)$ & 1.92 & 3 & 0.589 \\
\hline Only children 5 or younger & $(213 / 602)$ & $39.6(33.7,45.8)$ & & & \\
\hline Only children aged 6 to 14 & $(207 / 706)$ & $35.4(29.3,42.1)$ & & & \\
\hline Children 14 or younger & $(251 / 813)$ & $34.7(27.5,42.7)$ & & & \\
\hline \multicolumn{6}{|l|}{ No. household smokers } \\
\hline 1 & $(314 / 1084)$ & $35.1(28.9,41.9)$ & 2.61 & 2 & 0.271 \\
\hline 2 & $(413 / 1253)$ & $35.4(30.6,40.6)$ & & & \\
\hline 3 or more & $(174 / 547)$ & $40.5(33.6,47.9)$ & & & \\
\hline \multicolumn{6}{|l|}{ Tobacco use status } \\
\hline Exclusive cigarette smoker & $(735 / 2336)$ & $37.3(31.7,43.3)$ & 5.84 & 2 & 0.054 \\
\hline Exclusive bidi smoker & $(94 / 365)$ & $28.1(21.5,35.7)$ & & & \\
\hline Dual user & $(72 / 183)$ & $42.7(33.3,52.7)$ & & & \\
\hline
\end{tabular}


Table 3 Smoking behaviours associated with intentions to quit among all tobacco smokers (weighted, $n=2884$ )

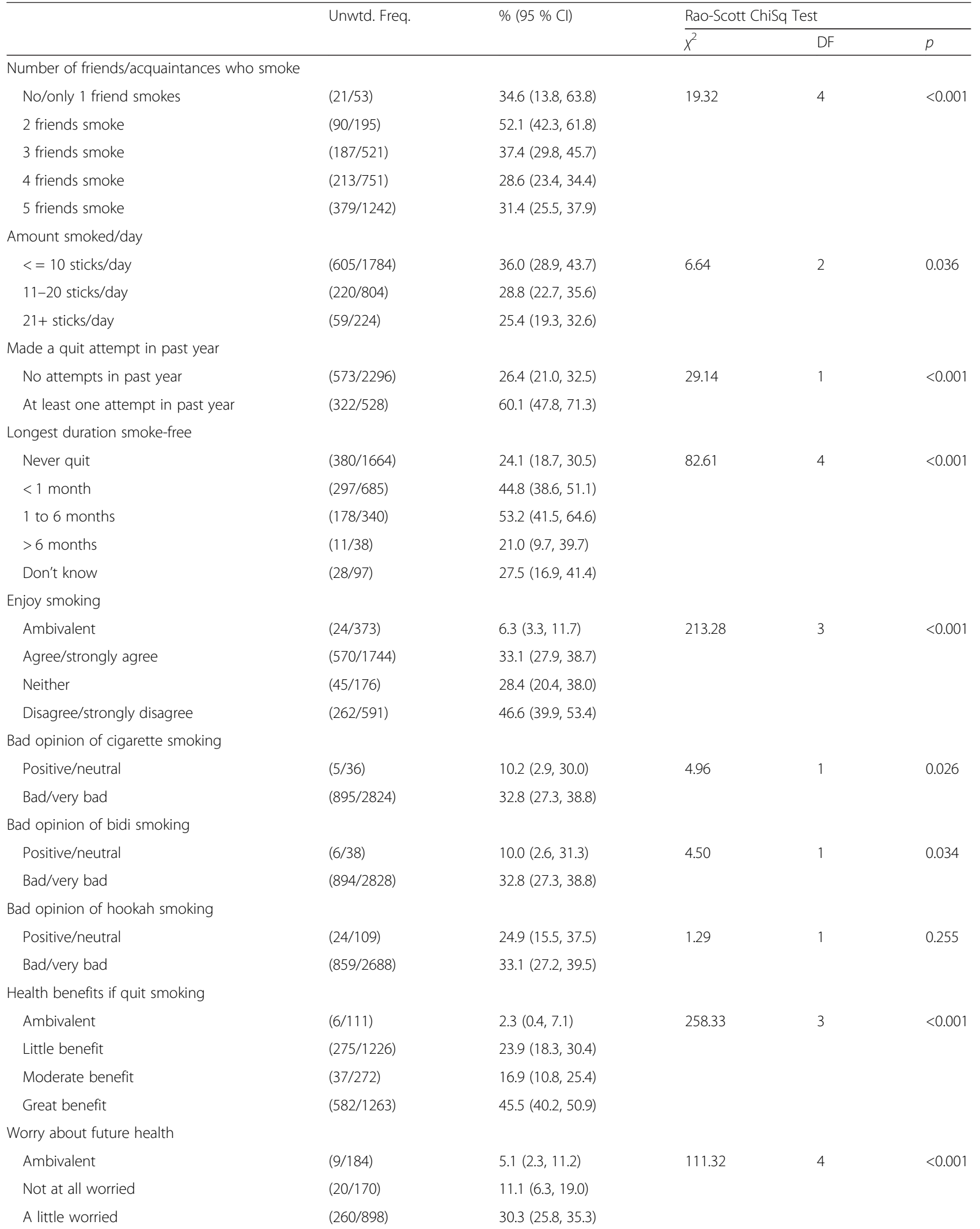


Table 3 Smoking behaviours associated with intentions to quit among all tobacco smokers (weighted, $n=2884$ ) (Continued)

\begin{tabular}{|c|c|c|c|c|c|}
\hline Moderately worried & $(432 / 1231)$ & $35.2(28.1,43.1)$ & & & \\
\hline Very worried & $(178 / 389)$ & $50.2(41.7,58.6)$ & & & \\
\hline \multicolumn{6}{|l|}{ Noticed warning labels } \\
\hline Unaware of labels & $(79 / 424)$ & $21.3(16.1,27.5)$ & 16.57 & 2 & $<0.001$ \\
\hline Never/once in a while & $(325 / 937)$ & $36.6(30.0,43.8)$ & & & \\
\hline Often/whenever smoke & $(488 / 1439)$ & $34.2(27.8,41.1)$ & & & \\
\hline \multicolumn{6}{|l|}{ Workplace smoking policy } \\
\hline Employed, policy not reported & $(57 / 159)$ & $38.9(26.5,52.9)$ & 32.13 & 4 & $<0.001$ \\
\hline Not employed outside home & $(440 / 1148)$ & $39.8(33.5,46.4)$ & & & \\
\hline Employed, does not work indoors & $(255 / 1112)$ & $24.5(19.2,30.8)$ & & & \\
\hline No/partial restrictions only & $(71 / 244)$ & $30.9(22.8,40.3)$ & & & \\
\hline Smoking not allowed indoors & $(77 / 211)$ & $31.6(21.7,43.7)$ & & & \\
\hline \multicolumn{6}{|l|}{$\begin{array}{l}\text { Received advice from doctor to } \\
\text { quit smoking }\end{array}$} \\
\hline Did not visit doctor & $(627 / 2128)$ & $30.1(25.0,35.9)$ & 33.74 & 2 & $<0.001$ \\
\hline Visited, no advice to quit & $(90 / 392)$ & $24.8(17.9,33.2)$ & & & \\
\hline Visited \& advised to quit & $(183 / 363)$ & $51.4(40.6,62.0)$ & & & \\
\hline \multicolumn{6}{|l|}{ Knowledge of smoking harms ${ }^{a}$} \\
\hline Low & $(135 / 821)$ & $20.5(11.7,33.4)$ & 28.26 & 2 & $<0.001$ \\
\hline Moderate & $(177 / 619)$ & $31.0(25.9,36.7)$ & & & \\
\hline High & $(589 / 1443)$ & $48.3(43.8,52.8)$ & & & \\
\hline \multicolumn{6}{|l|}{ Knowledge of effects of SHS } \\
\hline Low & $(155 / 869)$ & $19.0(11.5,29.9)$ & 38.29 & 2 & $<0.001$ \\
\hline Moderate & $(124 / 432)$ & $36.0(28.0,44.8)$ & & & \\
\hline High & $(900 / 2870)$ & $48.5(44.5,52.5)$ & & & \\
\hline
\end{tabular}

${ }^{a}$ Knowledge indices were ranked into approximate tertiles to explore the relationship between knowledge and quit intentions

should incorporate smoking cessation within its service framework.

Many of the predictors of quit intentions identified in this study are similar to those identified in previous studies with some differences. Contradicting the findings of previous studies [8-10], demographic factors such as age, gender, income, education were not predictors of intention to quit smoking in the current study. The lack of demographic differences in quit intentions might be related to the socio-cultural differences that might encourage smoking and quitting. However, the relation between demographic characteristics and intentions to quit are not always consistent [23, 31].

Previous studies have noted that nicotine dependence predicts smoking cessation and quit intentions [32-34]. In the current study, smoking fewer cigarettes per day, a proxy measure of nicotine dependence, was an independent predictor of quit intentions. This suggests that physical dependence could affect one's desire to quit smoking and underscores the need to tailor smoking cessation strategies based on the smokers' level of nicotine dependence $[35,36]$.
The relationship between smoking restrictions and intention to quit is not well studied. In a study of Korean adults [22], intention to quit was associated with home smoking restrictions but not with workplace smoking restrictions. In another study, both household and workplace smoking restrictions were associated with intention to quit and successful cessation [37]. In our study, workplace smoking policy predicted intentions to quit. This finding reinforces the fact that smoking bans may increase smokers' motivation to think about quitting and encourage them to attempt to quit [37] thereby promoting smoking cessation. Any policy implementation should be assesses periodically for reinforcement, because the impact of a new policy on smokers' intentions to quit may peak initially and then subside as time passes since the policy was implemented [33, 38].

The finding that past quitting efforts (i.e. tried to quit in the past) were associated with quit intentions compared to making no effort (i.e. never tried), is of note. These findings are likely due to differences in smokers' readiness to quit, because past quitters who are already motivated may try again while smokers without prior 
Table 4 Predictors $^{\mathrm{a}}$ of intentions to quit (any intention vs no intention) among all tobacco smokers $(n=2637)$

\begin{tabular}{|c|c|c|c|c|}
\hline & OR $(95 \% \mathrm{Cl})$ & $x^{2}$ & DF & $p$ value \\
\hline \multicolumn{5}{|l|}{ Sampling area } \\
\hline Dhaka non-slum areas vs. Dhaka slums & $1.34(0.43,4.20)$ & 23.83 & 3 & $<0.001$ \\
\hline Areas outside Dhaka vs. Dhaka slums & $2.47(1.08,5.63)$ & & & \\
\hline Tribal \& border areas vs. Dhaka slums & $0.69(0.29,1.66)$ & & & \\
\hline \multicolumn{5}{|l|}{ Sex } \\
\hline Women vs. men & $1.78(0.77,4.10)$ & 1.84 & 1 & 0.175 \\
\hline \multicolumn{5}{|l|}{ Age group } \\
\hline $25-39$ vs. $15-24$ & $0.84(0.59,1.18)$ & 4.65 & 3 & 0.199 \\
\hline $40-54$ vs. $15-24$ & $0.96(0.62,1.48)$ & & & \\
\hline $55+$ vs. $15-24$ & $1.10(0.80,1.51)$ & & & \\
\hline \multicolumn{5}{|l|}{ Type of smoker } \\
\hline Cigarette vs. dual user & $0.75(0.47,1.18)$ & 1.65 & 2 & 0.437 \\
\hline Bidi vs. dual user & $0.83(0.57,1.20)$ & & & \\
\hline \multicolumn{5}{|l|}{ Children at home } \\
\hline Only children 5 or younger vs. no children & $1.62(1.24,2.12)$ & 19.71 & 3 & $<0.001$ \\
\hline Only children 6-14 vs. no children & $1.00(0.77,1.28)$ & & & \\
\hline Children in both age groups vs. no children & $0.82(0.61,1.08)$ & & & \\
\hline \multicolumn{5}{|l|}{ Amount smoked per day (cigarettes and/or bidis) } \\
\hline 10 or fewer vs. $21+$ sticks/day & $2.08(1.34,3.22)$ & 13.93 & 2 & $<0.001$ \\
\hline $11-20$ vs. $21+$ sticks/day & $1.59(0.87,2.90)$ & & & \\
\hline \multicolumn{5}{|l|}{ Made a quit attempt in past year } \\
\hline At least one attempt vs none & $2.79(1.70,4.56)$ & 16.68 & 1 & $<0.001$ \\
\hline \multicolumn{5}{|l|}{ Enjoys smoking } \\
\hline Does not enjoy smoking vs. enjoys smoking & $1.45(1.00,2.08)$ & 47.24 & 3 & $<0.001$ \\
\hline Neither enjoys/not enjoy vs. enjoys smoking & $1.08(0.73,1.61)$ & & & \\
\hline Ambivalent vs. enjoys smoking & $0.18(0.09,0.36)$ & & & \\
\hline \multicolumn{5}{|l|}{ Perceptions about the benefit of quitting } \\
\hline Great benefit if quit vs. little benefit & $2.10(1.63,2.72)$ & 83.32 & 3 & $<0.001$ \\
\hline Moderate benefit if quit vs. little benefit & $0.71(0.48,1.06)$ & & & \\
\hline Ambivalent vs. little benefit & $0.01(0.00,0.08)$ & & & \\
\hline \multicolumn{5}{|l|}{ Worry about the health consequences of smoking } \\
\hline Very worried about health effects vs. Not at all & $8.66(3.89,19.28)$ & 44.66 & 4 & $<0.001$ \\
\hline Moderately worried vs. Not at all & $4.28(1.88,9.74)$ & & & \\
\hline A little worried vs. Not at all & $3.95(1.82,8.59)$ & & & \\
\hline Ambivalent vs. Not at all & $0.95(0.36,2.50)$ & & & \\
\hline \multicolumn{5}{|l|}{ Noticed warning labels on tobacco packaging } \\
\hline Often/whenever smoke vs. unaware of warning labels & $0.67(0.44,1.04)$ & 7.06 & 2 & 0.029 \\
\hline Never/rarely vs. unaware of warning labels & $0.97(0.63,1.50)$ & & & \\
\hline \multicolumn{5}{|l|}{ Workplace smoking policy } \\
\hline Not allowed indoors vs. does not work indoors & $1.96(1.32,2.91)$ & 22.77 & 4 & $<0.001$ \\
\hline No/partial bans vs. does not work indoors & $1.73(1.15,2.61)$ & & & \\
\hline Does not work outside home vs. does not work indoors & $1.47(1.11,1.95)$ & & & \\
\hline Employed, policy not reported vs. does not work indoors & $1.97(1.21,3.19)$ & & & \\
\hline
\end{tabular}


Table 4 Predictors $^{\mathrm{a}}$ of intentions to quit (any intention vs no intention) among all tobacco smokers $(n=2637)$ (Continued)

\begin{tabular}{|c|c|c|c|c|}
\hline \multicolumn{5}{|l|}{ Visited doctor in last year } \\
\hline Visited \& received advice vs. did not visit & $1.86(1.31,2.63)$ & 18.42 & 2 & $<0.001$ \\
\hline Visited, no advice vs. did not visit & $0.50(0.25,0.98)$ & & & \\
\hline \multicolumn{5}{|l|}{ Knowledge about the harms of smoking } \\
\hline 1 point increase & $1.08(0.99,1.18)$ & 2.75 & 1 & 0.097 \\
\hline \multicolumn{5}{|c|}{ Knowledge about the harms of second-hand smoke } \\
\hline 1 point increase & $1.20(1.08,1.33)$ & 12.55 & 1 & $<0.001$ \\
\hline
\end{tabular}

${ }^{a}$ Odds ratios were estimated from a weighted multivariable logistic regression model that accounts for the complex sampling design. Reported odds ratios are therefore adjusted odds ratios that control for all other covariates included in the model

attempts may simply not be ready to quit and therefore have no intention to quit. This suggests the need to motivate smokers to think about quitting by raising awareness of the benefits of quitting smoking. This should also encourage smokers to make frequent quit attempts, regardless of perceived likelihood of success on that quit attempt. In a study of Chinese adult smokers by Feng et al. [23], past quitting experience predicted subsequent quitting attempts. In this study perceptions about the benefit of quitting was strongly associated with intention to quit smoking, underscoring the need for policies that would focus on improving the perception of benefits of quitting smoking, probably through the educational campaign [4, 29].

The findings of the independent effect of motivational variables (i.e. worry about the harms of smoking, perception about benefits of quitting, enjoying smoking) on intentions to quit smoking in the current study is consistent with earlier studies among Chinese [23], Korean [22] and the Dutch smokers [38]. Increased knowledge about the harms of second hand smoke also predicted quit intentions in the current study reflecting the need to maintain adequate knowledge level among the public. Educational campaigns should focus on increasing public knowledge and awareness about the harms of tobacco and promote the benefits of smoking cessation.

We found that having a young child at home predicted quit intentions among Bangladeshi adults. This might be due to their increased knowledge about the harms of second-hand smoke (SHS) exposure as was found in the current study and their concern about childhood SHS exposure [26]. In our earlier study using ITC Wave 1 data, $89 \%$ of parents appropriately knew that SHS exposure may cause asthma in children [26]. The same study also reported that being concerned about a child's SHS exposure was a predictor of adopting a smoke-free policy in the home. Tobacco control strategies should continue with awareness campaigns to maintain high levels of knowledge about smoking and SHS, and to raise awareness of smoking and SHS exposure among the public. Utilizing child's health as a motivating factor, engaging pediatricians to encourage smoking parents to think about quitting and making quit attempt is effective [39], which would benefit both smokers and their children. Our findings showed that visiting a doctor and receiving advice predicted smokers' intention to quit. This reinforces the fact that doctor's advice, even if it is only brief advice, is effective in promoting smoking cessation [40, 41]. Physicians should be encouraged to routinely identify whether their patients smoke and provide them with brief advice to quit or to at least make an attempt to quit [42].

The current study has several limitations. First, our analysis was limited to daily smokers, so the findings may not be applicable to non-daily smokers. However, according to Wave 1 data, $96 \%$ of cigarette smokers/ dual users smoke cigarettes daily and $94 \%$ of dual users smoke bidis daily. Thus, our results represent the vast majority of smokers in Bangladesh. Second, nicotine dependence has been reported as a predictor of smoking cessation and quitting intentions in previous studies [32-34]. However, we were unable to include nicotine dependence as a predictor of intentions due to the way the data were collected in Wave 1 . We tried to compensate for this by using the total number of cigarettes smoked per day as a proxy measure of dependence.

\section{Conclusions}

The present study identified several predictors of intention to quit among Bangladeshi smokers, including past quitting experience, the number of cigarettes smoked daily, having a young child (aged 5 or younger) at home, health concerns, health services utilization and motivational factors. These predictors are fairly similar to those found among smokers in other developed countries. Population based tobacco control programs and policies should consider these predictors in the design of interventions to increase quitting among smokers in Bangladesh. At the same time, measures are necessary to increase intentions to quit among current smokers, because intention to quit is the first step towards the goal of quitting smoking completely. These findings has implications for Bangladesh and other developing countries, especially those in the Southeast Asia region, to strengthen the current tobacco control policies by incorporating smoking cessation within 
the policy agenda while promoting smoking ban in public places, workplaces and home.

\section{Acknowledgements}

We thank all the subjects for their participation in the study.

\section{Funding}

The ITC Bangladesh Project was supported by the International Development Research Centre (IDRC Grant 104831-002), Canadian Institutes for Health Research (Operating Grants 79551 and 115016), the US National Cancer Institute (P01 CA138389). Additional support was provided to Geoffrey T. Fong from a Senior Investigator Award from the Ontario Institute for Cancer Research and a Prevention Scientist Award from the Canadian Cancer Society Research Institute. ASA was supported by a Clinical Innovator Award from the Flight Attendant Medical Research Institute, USA through a grant to the American Academy of Pediatrics (AAP) Julius B. Richmond Center.

\section{Availability of data and materials}

All relevant data are within the paper. Additional data could be available upon request to the corresponding author.

\section{Authors' contributions}

GTF, NN, ASA planned the study. ACKQ coordinated the overall implementation of the project. NN directed the project implementation and field work in Bangladesh. ASA and PD jointly took the lead to draft the paper. PD conducted all the analyses and gave critical comments on the initial drafts. All authors approved the final draft of the paper.

\section{Competing interests}

The authors declare that they have no competing interests.

\section{Consent for publication}

All authors provided consent for this publication.

\section{Ethics approval and consent to participate}

Ethical approval was obtained from the Office of Research Ethics at the University of Waterloo (Waterloo, Canada), and the Ethical Review Committee, Bangladesh Medical Research Council. App participants provided written consent to participate in the study.

\section{Author details}

'Department of Psychology, University of Waterloo, Waterloo, ON, Canada. ${ }^{2}$ Global Health Program, Duke Kunshan University, Kunshan, Jiangsu Province 215347, China. ${ }^{3}$ Duke Global Health Institute, Duke University, Durham, NC 27710, USA. ${ }^{4}$ Department of General Internal Medicine, Boston University School of Medicine, Boston Medical Center, 801 Massachusetts Avenue, Crosstown Center (2nd Floor), Boston, MA 02118, USA. ${ }^{5}$ Department of Economics, University of Dhaka, Dhaka, Bangladesh. ${ }^{6}$ American Cancer Society, Washington DC, USA. ${ }^{7}$ Ontario Institute for Cancer Research, Toronto, ON, Canada.

\section{Received: 9 May 2016 Accepted: 9 August 2016}

Published online: 17 August 2016

\section{References}

1. Jha P, Peto R. Global effects of smoking, of quitting, and of taxing tobacco. N Engl J Med. 2014;370(1):60-8. doi:10.1056/NEJMra1308383.

2. Peto R, Lopez AD, Boreham J, Thun M. Mortality from smoking in developed countries, 1950-2010. Oxford: Clinical Trial Service Unit and Epidemiological Studies Unit; 2012. http://www.ctsu.ox.ac.uk/ tobacco.

3. Jha P. Avoidable global cancer deaths and total deaths from smoking. Nat Rev Cancer. 2009;9:655-64.

4. Abdullah AS, Husten CG. Promotion of smoking cessation in developing countries: a framework for urgent public health interventions. Thorax. 2004;59(7):623-30.

5. Prochaska JO, Velicer WF, DiClemente CC, Fava J. Measuring processes of change: applications to the cessation of smoking. J Consult Clin Psychol. 1988;56:520-8.

6. Bunton R, Baldwin S, Flynn D. The stages of change model and its use in health promotion: a critical review. Edinburgh: Health Education Board for Scotland; 1999.
7. DiClemente CC, Prochaska JO, Fairhurst SK, et al. The process of smoking cessation: an analysis of precontemplation, contemplation, and preparation stages of change. J Consult Clin Psychol. 1991;59:295e304.

8. Nides MA, Rakos RF, Gonzales D, et al. Predictors of initial smoking cessation and relapse through the first 2 years of the Lung Health Study. J Consult Clin Psychol. 1995;63(1):60e9.

9. Venters MH, Kottke TE, Solberg LI, et al. Dependency, social factors, and the smoking cessation process: the doctors helping smokers study. Am J Prev Med. 1990;6:185e93.

10. Vanasse A, Niyonsenga T, Courteau J. Smoking cessation within the context of family medicine: which smokers take action? Prev Med. 2004;38:330e7.

11. Tucker JS, Ellickson PL, Orlando M, et al. Predictors of attempted quitting and cessation among young adult smokers. Prev Med. 2005;41:554e61.

12. Clark MA, Hogan JW, Kviz FJ, Prohaska TR. Age and the role of symptomatology in readiness to quit smoking. Addict Behav. 1999;24:1-16.

13. Nguyen MN, Beland F, Otis J. Is the intention to quit smoking influenced by other heart-healthy lifestyle habits in 30- to 60-year-old men? Addict Behav. 1998;23:23-30.

14. Hu SC, Lanese RR. The applicability of the theory of planned behavior to the intention to quit smoking across workplaces in southern Taiwan. Addict Behav. 1998;23:225-37.

15. Orleans $C T$, Schoenbach VJ, Salmon MA, et al. A survey of smoking and quitting patterns among black Americans. Am J Public Health. 1989;79:176-81.

16. Marques-Vidal P, Melich-Cerveira J, Paccaud F, Waeber G, Vollenweider $P$, Cornuz J. Prevalence and factors associated with difficulty and intention to quit smoking in Switzerland. BMC Public Health. 2011;13(11):227. doi:10.1186/ 1471-2458-11-227.

17. Sorensen G, Emmons K, Stoddard AM, Linnan L, Avrunin J. Do social influences contribute to occupational differences in quitting smoking and attitudes toward quitting? Am J Health Promot. 2002;16:135-41.

18. Royce HM, Hymowitz N, Corbett K, Hartwell TD, Orlandi MA. Smoking cessation factors among African Americans and Whites. Am J Public Health. 1993;83:220-6.

19. Woods MN, Harris KJ, Ahluwalia JS, Schmelzle KH, Mayo MS. Smoking in urban African Americans: behaviors, gender difference, and motivation to quit. Ethn Dis. 2001;11:532-9.

20. Hutchison KE, Stevens VM, Collins Jr FL. Cigarette smoking and the intention to quit among pregnant smokers. J Behav Med. 1996;9:307-16.

21. Kraft P, Svendsen T, Hauknes A. Intention to stop smoking among Norwegian smokers: the role of nicotine dependence, type of cigarettes, and age at onset of daily smoking. Addict Behav. 1998;23:133-7.

22. Myung SK, Seo HG, Cheong YS, Park S, Lee WB, Fong GT. Association of sociodemographic factors, smoking-related beliefs, and smoking restrictions with intention to quit smoking in Korean adults: findings from the ITC Korea Survey. J Epidemiol. 2012;22(1):21-7. PMID: 22186157.

23. Feng G, Jiang Y, Li Q, Yong HH, Elton-Marshall T, Yang J, Li L, Sansone N, Fong GT. Individual-level factors associated with intentions to quit smoking among adult smokers in six cities of China: findings from the ITC China Survey. Tob Control. 2010;19 Suppl 2:i6-11. doi:10.1136/tc.2010.037093. PMID: 20935198

24. World Health Organization (WHO). Global adult tobacco survey (GATS): Bangladesh. Geneva: World Health Organization; 2009. Available from: http:// www.searo.who.int/LinkFiles/Regional_Tobacco_Surveillance_System_GATSBAN_ FullReport2009.pdf.

25. Abdullah AS, Driezen P, Quah AC, Nargis N, Fong GT. Predictors of smoking cessation behavior among Bangladeshi adults: findings from ITC Bangladesh survey. Tob Induc Dis. 2015;13(1):23. doi:10.1186/s12971-015-0050-y. PMID: 26261450, eCollection 2015.

26. Fong GT, Cummings KM, Borland R, Hastings G, Hyland A, Giovino G, Thompson ME. The conceptual framework of the International Tobacco Control (ITC) Policy Evaluation Project. Tob Control. 2006;15:i3-11. doi:10.1136/tc.2005.015438.

27. Abdullah AS, Hitchman SC, Driezen P, Nargis N, Quah AC, Fong GT. Socioeconomic differences in exposure to tobacco smoke pollution (TSP) in Bangladeshi households with children: findings from the International Tobacco Control (ITC) Bangladesh Survey. Int J Environ Publ Health Res. 2011;8(3):842-60.

28. ITC Project. ITC Bangladesh Wave 1 Technical Report. Waterloo and Dhaka: University of Waterloo and University of Dhaka; 2010. http://itcproject.org/ files/Report_Publications/National_Report/bd1trfinalapr21.pdf.

29. Abdullah AS, Yam HK. Intention to quit smoking, attempts to quit, and successful quitting among Hong Kong Chinese smokers: population prevalence and predictors. Am J Health Promot. 2005;19(5):346-54. 
30. Hyland A, Laux FL, Higbee C, et al. Cigarette purchase patterns in four countries and the relationship with cessation: findings from the International Tobacco Control (ITC) Four Country Survey. Tob Control. 2006;15 Suppl 3:iii59e64.

31. Siahpush $\mathrm{M}$, Borland $\mathrm{R}$, Yong $\mathrm{HH}$, et al. Socio-economic variations in tobacco consumption, intention to quit and self-efficacy to quit among male smokers in Thailand and Malaysia: results from the International Tobacco Control-South-East Asia (ITC-SEA) survey. Addiction. 2008:103:502e8.

32. Abdullah AS, Ho LM, Kwan YH, Cheung WL, McGhee SM, Chan WH. Promoting smoking cessation among the elderly: what are the predictors of intention to quit and successful quitting? J Aging Health. 2006;18(4):552-64.

33. Hyland A, Borland R, Li Q, Yong H-H, MCNeill A, Fong GT, O'Connor RJ, Cummings KM. Individual-level predictors of cessation behaviours among participants in the International Tobacco Control (ITC) Four Country Survey. Tob Control. 2006:15:83-94. doi:10.1136/tc.2005.013516.

34. Fagan $\mathrm{P}$, Augustson $\mathrm{E}$, Backinger $\mathrm{CL}$, et al. Quit attempts and intention to quit cigarette smoking among young adults in the United States. Am J Public Health. 2007;97:1412e20.

35. Etter JF, Laszlo E, Zellweger JP, et al. Nicotine replacement to reduce cigarette consumption in smokers who are unwilling to quit: a randomized trial. J Clin Psychopharmacol. 2002;22:487e95.

36. Hughes JR, Carpenter MJ. The feasibility of smoking reduction: an update. Addiction. 2005;100:1074e89.

37. Farkas JA, Gilpin EA, Distefan MJ, Pierce JP. The effects of household and workplace smoking restrictions on quitting behaviors. Tob Control. 1999;8:261-5.

38. Willemsen MC, De Vries H, van Breukelen G, Oldenburg B. Determinants of intention to quit smoking among Dutch employees: the influence of the social environment. Prev Med. 1996;25:195-202.

39. Winickoff JP. Pediatrician-led program increases provision of smoking cessation support, boosts quit rates among parents. Innov Med 2011, Accessed on 15 May 2012 at [http://innovations.ahrq.gov/content.aspx? id=2580].

40. Lin PR, Zhao ZW, Cheng KK, Lam TH. The effect of physician's 30 s smoking cessation intervention for male medical outpatients: a pilot randomized controlled trial. J Public Health (Oxf). 2013;35(3):375-83. doi:10.1093/ pubmed/fdt018. PMID: 23487178

41. Kottke TE, Battista RN, DeFriese GH, Brekke ML. Attributes of successful smoking cessation interventions in medical practice. A meta-analysis of 39 controlled trials. JAMA. 1988;259:2883-9.

42. Fiore MC, Bailey WC, Cohen SJ, et al. Treating Tobacco Use and Dependence, Clinical Practice Guideline. Rockville: Public Health Service; 2000.

\section{Submit your next manuscript to BioMed Central and we will help you at every step:}

- We accept pre-submission inquiries

- Our selector tool helps you to find the most relevant journal

- We provide round the clock customer support

- Convenient online submission

- Thorough peer review

- Inclusion in PubMed and all major indexing services

- Maximum visibility for your research

Submit your manuscript at www biomedcentral.com/submit

Biomed Central 